\title{
Flaxseed oil prevents trans-10, cis-12-conjugated linoleic acid-induced insulin resistance in mice
}

\author{
Darshan S. Kelley ${ }^{1}{ }^{*}$, Madhuri Vemuri ${ }^{1}$, Yuriko Adkins ${ }^{1}$, Sher Himmat S. Gill ${ }^{1}$, Dawn Fedor ${ }^{1}$ \\ and Bruce E. Mackey ${ }^{2}$ \\ ${ }^{1}$ Western Human Nutrition Research Center, ARS, USDA, and Department of Nutrition, University of California, Davis, 430 West \\ Health Sciences Drive, Davis, CA 95616, USA \\ ${ }^{2}$ Western Regional Research Center, ARS, USDA, Albany, CA, USA
}

(Received 21 February 2008 - Revised 3 June 2008 - Accepted 5 June 2008 - First published online 19 August 2008)

Insulin resistance (IR) and non-alcoholic fatty liver disease (NAFLD) are found in 35 and $30 \%$ of US adults, respectively. Trans-10, cis12-conjugated linoleic acid (CLA) has been found to cause both these disorders in several animal models. We hypothesised that IR and NAFLD caused by CLA result from $n-3$ fatty acid deficiency. Pathogen-free C57BL/6N female mice (aged 8 weeks; $n 10$ ) were fed either a control diet or diets containing trans-10, cis-12-CLA $(0.5 \%)$ or CLA + flaxseed oil (FSO) $(0.5 \%+0.5 \%)$ for 8 weeks. Weights of livers, concentration of circulating insulin, values of homeostatic model 1 (HOMA1) for IR and HOMA1 for $\beta$ cell function were higher by $160,636,985$ and $968 \%$ in the CLA group compared with those in the control group. FSO decreased fasting glucose by $20 \%$ and liver weights by $37 \%$ compared with those in the CLA group; it maintained circulating insulin, HOMA1-IR and HOMA1 for $\beta$ cell function at levels found in the control group. CLA supplementation decreased $n-6$ and $n-3$ wt $\%$ concentrations of liver lipids by 57 and $73 \%$ and increased the $n-6: n-3$ ratio by $58 \%$ compared with corresponding values in the control group. FSO increased $n-6$ and $n-3$ PUFA in liver lipids by 33 and $342 \%$ and decreased the $n-6: n-3$ ratio by $70 \%$ compared with corresponding values in the CLA group. The present results suggest that some adverse effects of CLA may be due to $n$ - 3 PUFA deficiency and that these can be corrected by a concomitant increase in the intake of $\alpha$-linolenic acid, $18: 3 n-3$.

$\alpha$-Linolenic acid: $n$-3 Polyunsaturated fatty acids: Non-alcoholic fatty liver disease: Cardiovascular disease

Insulin resistance (IR) is a condition in which normal amounts of insulin are inadequate to produce normal responses from fat, muscle (promote glucose uptake) and liver (inhibit glucose

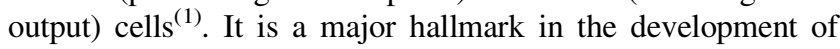
type 2 diabetes mellitus and a number of associated metabolic disorders including non-alcoholic fatty liver disease (NAFLD), lipoatrophy and $\mathrm{CVD}^{(2)}$. Based on the National Health and Nutrition Examination Survey (NHANES) conducted between 1999 and $2002,10 \%$ of adult US men and women were diabetic and $35 \%$ were hyperinsulinaemic (a surrogate marker for IR) ${ }^{(3,4)}$. NAFLD is a clinicopathological term that encompasses a disease spectrum ranging from simple TAG accumulation in hepatocytes (hepatic steatosis) to hepatic steatosis with inflammation (steatohepatitis), fibrosis and cirrhosis. It is the most common chronic liver condition in the Western world, and affects $30 \%$ of the adult population in the USA ${ }^{(5,6)}$. IR and NAFLD can be found independently, but they often occur concurrently ${ }^{(7-9)}$. Frequently NAFLD and IR are associated with obesity, type 2 diabetes mellitus and dyslipidaemia ${ }^{(2)}$, but they are also associated with deficiency of depot fat ${ }^{(10)}$.

Dietary factors that contribute to the development of IR and NAFLD include high-fat (saturated and trans-fatty acids) and high-sucrose diets ${ }^{(11-13)}$. One of the trans-fatty acids in the diet is conjugated linoleic acid (CLA), which refers to linoleic acid isomers having conjugated double bonds. Although vaccenic acid (trans-11-18:1) is the most abundant natural transfatty acid found in ruminant meat and dairy products, and elaidic acid (trans-9-18:1) is the most abundant trans-fatty acid in industrially hydrogenated oils ${ }^{(14)}$, concentrations of CLA isomers from foods can vary greatly depending upon the method of hydrogenation. The average intake of CLA in the USA has been estimated to be less than $0.5 \mathrm{~g} / \mathrm{d}^{(15)}$; however, actual intakes by individuals consuming processed oils may be several folds greater than this, because the concentration of all CLA isomers in partially hydrogenated oil was $9.8 \%$ of the total fatty acids and that of trans-10, cis-12-CLA was $2.6 \%^{(16)}$. Thus, the amounts of trans-10, cis-12-CLA consumed alone or along with other transfatty acids from partially hydrogenated or processed foods can reach levels beyond what is needed to induce IR and NAFLD. Supplementing animal diets with CLA has been reported to decrease body fat, while ectopically depositing fat in liver, muscle and other tissues ${ }^{(7,17)}$; however, results from human studies regarding health benefits of CLA are quite inconsistent ${ }^{(18,19)}$. Supplementing animal and human diets with CLA altered tissue lipids and their fatty acid composition, increased lipid peroxidation, inflammation, NAFLD, incidence of IR and diabetes ${ }^{(20-29)}$.

Abbreviations: ALA, $\alpha$-linolenic acid; CLA, conjugated linoleic acid; FSO, flaxseed oil; HOMA1, homeostatic model assessment 1; IR, insulin resistance; NAFLD, non-alcoholic fatty liver disease.

* Corresponding author: Dr Darshan Kelley, fax +1 530752 5271, email darshan.kelley@ars.usda.gov 
Trans-10, cis-12-CLA, and not cis-9, trans-11-CLA, is the isomer that reduces depot fats while causing fatty liver and IR, and these two isomers have contrasting effects on

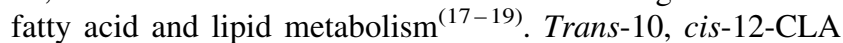
increased the liver concentrations of oleic acid (18:1n-9) and decreased those of $n-6$ and $n-3$ PUFA $^{(26,30)}$. NAFLD is associated with an increase in the hepatic $n-6: n-3$ ratio ${ }^{(31)}$. Animal diets usually have adequate amounts of $n-6$ PUFA, but many may be inadequate in $n-3$ PUFA. We therefore propose that the aggravation of $n-3$ PUFA inadequacy (increased ratio between $n-6$ and $n-3$ PUFA) by CLA exacerbates the development of fatty liver and IR; these CLA-induced pathologies could be prevented by the concomitant increase in the intake of $n$-3 PUFA. Fish oils that contain a mixture of EPA $(20: 5 n-3)$ and DHA $(22: 6 n-3)$ and purified DHA have been shown to prevent the development of IR and NAFLD induced by high-fat ${ }^{(32,33)}$ or high-sucrose ${ }^{(34)}$ diets and by diets containing a mixture of CLA isomers or purified trans-10, cis-12-CLA $^{(7,35,36)}$. Supplementing diets of obese rats and mice with $\alpha$-linolenic acid (ALA; 18:3n-3) prevented the development of NAFLD and $\mathrm{IR}^{(37,38)}$. It also prevented the sucrose-induced IR in non-obese rats ${ }^{(39)}$. To the best of our knowledge, none of the published reports have examined if concomitant supplementation with ALA will prevent the CLA-induced fatty liver and IR, which may involve different mechanisms from the obesity-related NAFLD and IR. The objective of the present study was to determine if ALA will prevent the development of fatty liver and IR induced by CLA. To address this question, we determined organ weights, liver and plasma lipids, and plasma concentrations of glucose and insulin in three groups of mice that were fed three different diets (control; control + CLA; control + CLA + flaxseed oil (FSO)). We also examined plasma concentrations of leptin, adiponectin, IL-6 and $\mathrm{TNF} \alpha$ because of their claimed roles in IR and glucose homeostasis. In addition, we determined the fatty acid composition of the liver to support our hypothesis.

\section{Research design and methods}

\section{Animals and diets}

The animal protocol was approved by the Animal Use Committee at the University of California, Davis. Pathogen-free C57BL/6N female mice, aged 8 weeks, were purchased from Charles River (Raleigh, NC, USA). Species, sex, and strain of the animals were based on the use of this model by us and other investigators in a large number of published studies with $\mathrm{CLA}^{(17)}$. The animals were maintained at the animal facility in the department of Nutrition, University of California, Davis. The temperature in the room was maintained at $25^{\circ} \mathrm{C}$ with dark and light cycles of $12 \mathrm{~h}$ each. Animals were fed the laboratory chow diet for week 1 and experimental diets for the subsequent 8 weeks. They were randomly divided into three groups (control; CLA; CLA + FSO) after feeding the laboratory chow diet for 1 week (ten animals per group).

An AIN 93G modified (soyabean oil replaced with maize oil) mouse diet was used as the basal diet as previously reported $^{(26)}$. The fatty acid composition of the experimental diets is shown in Table 1. Highly enriched trans-10, cis-12CLA $(97.6 \%$ purity) in the form of NEFA (Larodan Fine
Table 1. Fatty acid composition of the experimental diets (Mean values ( $n$ 4) with their standard errors for each fatty acid measured)

\begin{tabular}{|c|c|c|c|c|c|c|}
\hline \multirow{2}{*}{$\begin{array}{l}\text { Diet... } \\
\text { Fatty acid } \\
\text { (g/100 g total } \\
\text { fatty acids) }\end{array}$} & \multicolumn{2}{|c|}{ Control } & \multicolumn{2}{|c|}{ CLA } & \multicolumn{2}{|c|}{$\mathrm{CLA}+\mathrm{FSO}$} \\
\hline & Mean & SEM & Mean & SEM & Mean & SEM \\
\hline \multicolumn{7}{|l|}{ SFA } \\
\hline $16: 0$ & $12 \cdot 5^{\mathrm{c}}$ & 0.07 & $11 \cdot 2^{b}$ & 0.05 & $10 \cdot 4^{a}$ & 0.04 \\
\hline $18: 0$ & $2 \cdot 13^{b}$ & 0.03 & $1.94^{a}$ & 0.02 & $2 \cdot 06^{b}$ & 0.03 \\
\hline \multicolumn{7}{|l|}{ MUFA } \\
\hline $18: 1 n-9$ & $25 \cdot 0^{b}$ & 0.34 & $22 \cdot 5^{a}$ & 0.25 & $21 \cdot 7^{a}$ & 0.14 \\
\hline \multicolumn{7}{|l|}{ PUFA } \\
\hline $18: 2 n-6$ & $55 \cdot 2^{c}$ & 0.39 & $50 \cdot 1^{b}$ & 0.23 & $46 \cdot 7^{a}$ & 0.06 \\
\hline CLA & $0.02^{a}$ & 0.00 & $9 \cdot 71^{b}$ & 0.14 & $9 \cdot 81^{b}$ & 0.04 \\
\hline $18: 3 n-3$ & $1.04^{a}$ & 0.02 & $0.99^{a}$ & 0.01 & $6 \cdot 17^{b}$ & 0.16 \\
\hline$n-6: n-3$ ratio & $53 \cdot 0^{\mathrm{b}}$ & $1 \cdot 27$ & $60 \cdot 8^{c}$ & 0.39 & $9 \cdot 21^{a}$ & 0.25 \\
\hline $\begin{array}{l}\text { Minor or } \\
\text { unknown* }\end{array}$ & $4 \cdot 06^{b}$ & 0.38 & $3.33^{b}$ & 0.04 & $2 \cdot 89^{a}$ & 0.02 \\
\hline
\end{tabular}

CLA, trans-10, cis-12-conjugated linoleic acid; FSO, flaxseed oil.

${ }^{a, b, c}$ Mean values within a row with unlike superscript letters were significantly different $(P \leq 0.05$; ANOVA; $\mathrm{a}<\mathrm{b}<\mathrm{c})$.

${ }^{*}$ Fatty acids with concentrations less than $0.5 \mathrm{~g} / 100 \mathrm{~g}$ fatty acids are grouped as 'minor', unless their concentrations were significantly different between the three groups.

Chemicals, Malmö, Sweden) was used to provide the desired CLA concentration $(0.5 \mathrm{~g} / 100 \mathrm{~g}$ diet $)$; it was incorporated into the diet by replacing an equivalent amount of maize oil. In the CLA + FSO group, FSO replaced an equivalent amount of maize oil to provide FSO at $0.5 \mathrm{~g} / 100 \mathrm{~g}$ diet (ALA $0.3 \mathrm{~g} / 100 \mathrm{~g}$ diet or $6.2 \mathrm{~g} / 100 \mathrm{~g}$ dietary fatty acids). The $n-6: n-3$ ratios for the control, CLA and CLA + FSO diets were 53.0 (SEM 1.27), $60 \cdot 8$ (SEM 0.39) and 6.2 (SEM 0.25), respectively. The amount of CLA supplemented was comparable with the amounts used in previous studies with rodent models, which ranged from $0 \cdot 1$ to $1.5 \mathrm{~g} / 100 \mathrm{~g}$ diet of a mixture of CLA isomers ${ }^{(17-19)}$. The concentration of ALA was selected to mimic the linoleic acid $(18: 2 n-6)$ and ALA ratios (7:1) found in the AIN-93 diet ${ }^{(40)}$. Diets were constantly flushed with $\mathrm{N}_{2}$ gas to prevent oxidation of fatty acids while being gently mixed in a blender and packaged in $25 \mathrm{~g}$ samples. Packaged diets were stored at $-20^{\circ} \mathrm{C}$ until use. Fresh dietary packages were served each day and the food left in the cups from the previous day was weighed and recorded. Body weights were recorded every $7 \mathrm{~d}$. After feeding the experimental diets for 8 weeks, animals were killed between 08.00 and 11.00 hours after withholding food for $10-12 \mathrm{~h}$. They were anaesthetised with an intraperitoneal injection of ketamine $\mathrm{HCl}(100 \mathrm{mg} / \mathrm{kg}$ body weight) and xylazine $(8 \mathrm{mg} / \mathrm{kg}$ body weight). Blood was collected by heart puncture into syringes containing EDTA. Livers were then removed, blotted dry on tissue paper, weighed, frozen in liquid $\mathrm{N}_{2}$, and stored frozen at $-80^{\circ} \mathrm{C}$ until processing. Since we did not perfuse the livers, the results reported for liver lipids may reflect concentrations both in the liver and blood. Further details regarding animal handling and diets can be found in our earlier reports ${ }^{(26,41)}$.

\section{Liver and plasma lipids, plasma glucose and hormones}

Liver total lipids were extracted using previously published methods ${ }^{(26)}$. Briefly, a portion of the frozen liver was 
weighed, freeze-dried and transferred into a $7 \mathrm{ml}$ glass homogeniser. The sample was homogenised with $5 \mathrm{ml}$ chloroform-methanol $(2: 1, \mathrm{v} / \mathrm{v})$ containing $0.005 \%$ butylated hydroxytoluene, and $1 \mathrm{ml}$ of $1 \mathrm{M}$-sodium chloride. The homogenate was transferred to a screw-cap tube, centrifuged, and the lipid phase was removed into a $7 \mathrm{ml}$ culture tube. The residual tissue lipids were extracted with an additional $5 \mathrm{ml}$ chloroform - methanol (2:1, v/v) containing $0.005 \%$ butylated hydroxytoluene. The two lipid extracts were combined and dried under $\mathrm{N}_{2}$. The lipid residue was dissolved in $1 \mathrm{ml}$ chloroform, transferred to a tarred $2 \mathrm{ml}$ vial, freeze-dried, and weighed.

Plasma total cholesterol, LDL-cholesterol, HDL-cholesterol, TAG and NEFA were analysed by using standard automated enzymic methods. Plasma glucose was measured using a commercial glucose assay kit (Sigma Aldrich, St Louis, MO, USA). Concentrations of insulin, leptin and adiponectin were determined by using multiplex/uniplex assay kits (Millipore, Billerica, MA, USA). IR and $\beta$ cell function were calculated using the original homeostasis model assessment (homeostatic model assessment 1; HOMA1) of $\mathrm{IR}^{(42)}$. The equations used were:

$$
\text { HOMA1-IR }=(\text { FPI } \times \text { FPG }) / 22 \cdot 5,
$$

HOMA1 for percent $\beta$ cell function $=(20 \times \mathrm{FPI}) /(\mathrm{FPG}-3 \cdot 5)$,

where FPI is fasting plasma insulin concentration (mU/l) and FPG is fasting plasma glucose (mM).

\section{Statistical analysis}

The Box-Cox approach was used to estimate appropriate transformations ${ }^{(43)}$. In most cases for which a power transformation did not stabilise the variances, the data were transformed by ranks. The one-way model was fitted with SAS PROC GLM (SAS Institute, Inc., Cary, NC, USA), along with Levene's test for heterogeneity of variance and multiple comparisons among the treatment means using Tukey's adjustment for multiplicity ${ }^{(44)}$. The data shown are mean values with their standard errors, with $P \leq 0.05$ considered significantly different. Weekly body weights were analysed using the repeated-measures model with a first-order autoregressive covariance structure among the repeated measures. The diet means were compared using Tukey's adjustment for multiplicity $^{(45)}$.

\section{Results}

\section{Food intake and body and organ weights}

Mean daily food intake per mouse for the control, CLA and CLA + FSO groups was 4.53 (SEM 0.10), 4.61 (SEM 0.02) and 4.68 (SEM 0.01) g, respectively; it did not differ significantly between the three dietary groups. Initial body weights did not differ between the three groups, but weight gained during the first 7 weeks of feeding the experimental diets was significantly lower in the CLA and CLA + FSO groups compared with the weight gained in the control group $(P \leq 0.05$; Fig. 1). CLA also decreased the mean weights of perirenal and ovarian fat pads by 84 and $78 \%$ and increased those of livers by $160 \%$ compared with those in the control group (Table 2). Concomitant supplementation of FSO

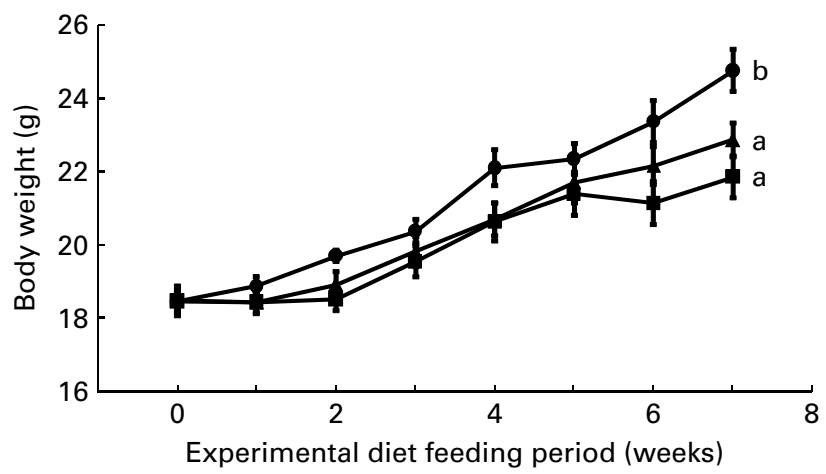

Fig. 1. Weekly body weights of mice fed control $(\bullet)$, trans-10, cis12-conjugated linoleic acid (CLA; $\mathbf{\square})$ or CLA + flaxseed oil $(\boldsymbol{\Lambda})$ diets. Data are means ( $n$ 10), with standard errors represented by vertical bars. Overall increases in body weights during the 7 weeks were compared and the lines with unlike letters are significantly different $(P<0.05)$, using a repeatedmeasures ANOVA and Tukey's test on the diet main-effect means (diet $X$ time, $P=0 \cdot 21$ )

and CLA partially prevented the CLA-induced changes in body, liver and adipose tissue weights. Compared with the CLA group the decrease in liver $(37 \%)$ and increase in perirenal adipose tissue $(60 \%)$ weights were significant $(P \leq 0.05)$, while the body and ovarian adipose tissue weights did not differ significantly between the CLA and CLA + FSO groups. Weights of spleens, kidneys, hearts and brains did not differ between the three groups (Table 2).

\section{Liver fatty acid composition}

Wt\% concentration of the liver lipid SFA did not differ between the mice fed the three different experimental diets, although there were minor and significant differences in the individual concentrations of 16:0 and 18:0 (Table 3). The total MUFA wt\% concentration in liver lipids was significantly increased $(35 \%)$ by feeding the CLA diet when compared with the corresponding values in the control group. The CLA + FSO diet decreased the wt $\%$ of total MUFA by $9 \%$ when compared with that in the CLA group (NS). The changes in the MUFA concentration were primarily due to changes in the concentration of $18: 1 n-9$. CLA supplementation decreased the wt $\%$ concentration of $n-6$ PUFA by $57 \%$ and that of $n-3$ PUFA by $73 \%$ when compared with the corresponding values in the control group; it increased the $n-6: n-3$ ratio by $58 \%$. The decrease in $n-6$ PUFA resulted from significant reductions in the concentrations of $18: 2$, $18: 3,20: 4$ and $22: 5$, while that in $n$-3 PUFA resulted from significant reductions in $18: 3,20: 5$ and $22: 6$. Concomitant supplementation of FSO with CLA increased the wt $\%$ of $n-6$ PUFA by $33 \%$ and that of $n-3$ PUFA by $342 \%$ as compared with the corresponding values in the CLA group. The increase in $n-6$ PUFA resulted from a $26 \%$ increase in the wt\% concentration of $18: 2 n-6$ (NS) and a $70 \%$ increase in that of $20: 4 n-6$; increases in $n-3$ PUFA resulted from 550, 300 and $323 \%$ increases in the wt $\%$ concentrations of $18: 3 n-3,20: 5 n-3$ and $22: 6 n-3$, respectively. FSO also decreased the $n-6: n-3$ ratio by $70 \%$ when compared with that found in the CLA group. Thus, CLA supplementation increased the wt $\%$ concentration of total MUFA and $n-6: n-3$ ratio and decreased the concentrations of both $n-6$ 
Table 2. Effect of experimental diets on selected organ weights of mice (Mean values $(n 10)$ with their standard errors for each variable measured)

\begin{tabular}{|c|c|c|c|c|c|c|}
\hline \multirow[b]{3}{*}{ Variable } & \multicolumn{6}{|c|}{ Dietary group } \\
\hline & \multicolumn{2}{|c|}{ Control } & \multicolumn{2}{|c|}{ CLA } & \multicolumn{2}{|c|}{$\mathrm{CLA}+\mathrm{FSO}$} \\
\hline & Mean & SEM & Mean & SEM & Mean & SEM \\
\hline Liver (g) & $1.03^{\mathrm{a}}$ & 0.06 & $2 \cdot 68^{c}$ & 0.18 & $1.67^{\mathrm{b}}$ & 0.07 \\
\hline Perirenal fat $(\mathrm{g})$ & $0.32^{\mathrm{c}}$ & 0.05 & $0.05^{\mathrm{a}}$ & 0.01 & $0.08^{\mathrm{b}}$ & 0.01 \\
\hline Ovarian fat $(\mathrm{g})$ & $0.81^{\mathrm{b}}$ & 0.07 & $0.18^{a}$ & 0.01 & $0.24^{a}$ & 0.02 \\
\hline Spleen (g) & 0.10 & 0.01 & 0.10 & 0.01 & 0.10 & 0.01 \\
\hline Kidney (g) & 0.29 & 0.01 & 0.28 & 0.01 & 0.28 & 0.01 \\
\hline Heart $(\mathrm{g})$ & 0.11 & 0.00 & 0.12 & 0.01 & 0.12 & 0.00 \\
\hline Brain (g) & 0.40 & 0.01 & 0.40 & 0.02 & 0.44 & 0.01 \\
\hline Total liver lipids (mg) & $101 \cdot 2^{\mathrm{a}}$ & 8.50 & $620 \cdot 5^{c}$ & $75 \cdot 3$ & $380^{\mathrm{b}}$ & 29.5 \\
\hline
\end{tabular}

CLA, trans-10, cis-12-conjugated linoleic acid; FSO, flaxseed oil.

$\mathrm{a}, \mathrm{b}, \mathrm{c}$ Mean values within a row with unlike superscript letters were significantly different $(P \leq 0.05$; ANOVA; $\mathrm{a}<\mathrm{b}<\mathrm{c})$.

and $n-3$ PUFA in liver lipids; FSO supplementation partially or completely reversed the changes in fatty acid composition induced by CLA.

Effects of dietary fatty acids on plasma lipids, glucose, hormones and cytokines

CLA supplementation did not alter the plasma concentrations of total cholesterol, HDL-cholesterol, LDL-cholesterol and NEFA when compared with the corresponding concentrations in the control group; however, it reduced the plasma TAG concentrations by $38 \%$ (Table 4). Concomitant supplementation of FSO and CLA reduced total cholesterol, HDLcholesterol and LDL-cholesterol by $30-38 \%$ and TAG by $57 \%$ when compared with those found in the CLA group.

CLA supplementation did not alter the fasting plasma glucose, but increased the concentration of circulating insulin, HOMA1-IR and HOMA1 for $\beta$ cell function by 636, 982 and $968 \%$, respectively as compared with the corresponding values in the control group (Table 4). It also lowered concentrations

Table 3. Fatty acid composition of livers of mice fed experimental diets

(Mean values $(n 5)$ with their standard errors for each fatty acid measured)

\begin{tabular}{|c|c|c|c|c|c|c|}
\hline \multirow[b]{3}{*}{ Fatty acid ( $\mathrm{g} / 100 \mathrm{~g}$ total fatty acids) } & \multicolumn{6}{|c|}{ Dietary group } \\
\hline & \multicolumn{2}{|c|}{ Control } & \multicolumn{2}{|c|}{ CLA } & \multicolumn{2}{|c|}{$\mathrm{CLA}+\mathrm{FSO}$} \\
\hline & Mean & SEM & Mean & SEM & Mean & SEM \\
\hline \multicolumn{7}{|l|}{ SFA } \\
\hline $16: 0$ & $25 \cdot 0^{a}$ & 0.61 & $27 \cdot 8^{\mathrm{b}}$ & 0.58 & $25 \cdot 7^{\mathrm{a}}$ & 0.55 \\
\hline $18: 0$ & $6 \cdot 14^{\mathrm{c}}$ & 0.30 & $3 \cdot 21^{\mathrm{a}}$ & 0.23 & $4 \cdot 32^{b}$ & 0.55 \\
\hline Total SFA & $31 \cdot 1^{\mathrm{a}}$ & 0.42 & $31.0^{\mathrm{a}}$ & 0.69 & $30 \cdot 0^{\mathrm{a}}$ & 0.94 \\
\hline \multicolumn{7}{|l|}{ MUFA } \\
\hline $16: 1 n-7$ trans & $0.54^{a}$ & 0.09 & $1 \cdot 37^{\mathrm{b}}$ & 0.12 & $1 \cdot 24^{b}$ & 0.10 \\
\hline $16: 1 n-7$ & $4.79^{b}$ & 0.51 & $4 \cdot 36^{b}$ & 0.11 & $2 \cdot 94^{\mathrm{a}}$ & 0.20 \\
\hline $18: 1 n-9$ & $33.5^{\mathrm{a}}$ & 1.87 & $46 \cdot 6^{\mathrm{b}}$ & 1.08 & $44 \cdot 3^{\mathrm{b}}$ & 2.36 \\
\hline $18: 1 n-7$ & $4 \cdot 03^{\mathrm{a}, \mathrm{b}}$ & 0.47 & $4.93^{\mathrm{b}}$ & 0.16 & $3.91^{a}$ & 0.23 \\
\hline $20: 1 n-9$ & $0.45^{\mathrm{a}}$ & 0.03 & $1.05^{\mathrm{b}}$ & 0.08 & $0.93^{\mathrm{b}}$ & 0.14 \\
\hline Total MUFA & $43 \cdot 3^{\mathrm{a}}$ & $2 \cdot 70$ & $58 \cdot 3^{\mathrm{b}}$ & 1.37 & $53 \cdot 3^{\mathrm{b}}$ & 2.57 \\
\hline \multicolumn{7}{|l|}{ PUFA } \\
\hline $18: 2 n-6$ & $11 \cdot 7^{b}$ & 1.75 & $5 \cdot 85^{a}$ & 0.38 & $7 \cdot 37^{a, b}$ & 0.50 \\
\hline CLA & $0.04^{a}$ & 0.01 & $0 \cdot 17^{b}$ & 0.01 & $0 \cdot 19^{\mathrm{b}}$ & 0.04 \\
\hline $18: 3 n-6$ & $0.50^{\mathrm{b}}$ & 0.13 & $0 \cdot 15^{a}$ & 0.01 & $0 \cdot 20^{a}$ & 0.05 \\
\hline $20: 4 n-6$ & $6 \cdot 13^{\mathrm{c}}$ & 0.66 & $1.68^{\mathrm{a}}$ & 0.23 & $2 \cdot 85^{\mathrm{b}}$ & 0.27 \\
\hline $22: 5 n-6$ & $0.68^{\mathrm{b}}$ & 0.10 & $0.23^{\mathrm{a}}$ & 0.06 & $0.15^{\mathrm{a}}$ & 0.04 \\
\hline Total $n-6$ PUFA & $19 \cdot 1^{\mathrm{c}}$ & 2.56 & $8 \cdot 12^{\mathrm{a}}$ & 0.66 & $10 \cdot 8^{\mathrm{b}}$ & 0.86 \\
\hline $18: 3 n-3$ & $0 \cdot 13^{b}$ & 0.02 & $0.04^{\mathrm{a}}$ & 0.00 & $0.26^{c}$ & 0.05 \\
\hline $20: 5 n-3$ & $0 \cdot 10^{\mathrm{b}}$ & 0.02 & $0.02^{a}$ & 0.01 & $0.08^{b}$ & 0.02 \\
\hline $22: 6 n-3$ & $1.46^{\mathrm{b}}$ & 0.29 & $0.39^{\mathrm{a}}$ & 0.05 & $1.65^{\mathrm{b}}$ & 0.19 \\
\hline Total $n-3$ PUFA & $1.69^{\mathrm{b}}$ & 0.31 & $0.45^{\mathrm{a}}$ & 0.05 & $1.99^{\mathrm{b}}$ & 0.22 \\
\hline Total PUFA & $20 \cdot 8^{\mathrm{b}}$ & $2 \cdot 87$ & $8.57^{a}$ & 0.71 & $12 \cdot 8^{\mathrm{b}}$ & 1.04 \\
\hline$n-6: n-3$ ratio & $11.9^{\mathrm{b}}$ & 0.79 & $18 \cdot 8^{\mathrm{C}}$ & 1.54 & $5 \cdot 55^{\mathrm{a}}$ & 0.40 \\
\hline Minor or unknown* & $4 \cdot 73^{\mathrm{b}}$ & 0.55 & $2 \cdot 19^{a}$ & 0.27 & $3.89^{b}$ & 0.72 \\
\hline
\end{tabular}

CLA, trans-10, cis-12-conjugated linoleic acid; FSO, flaxseed oil.

${ }_{a, b, c}$ Mean values within a row with unlike superscript letters were significantly different $(P \leq 0.05$; ANOVA; $a<b<c)$.

${ }^{*}$ Fatty acids with concentrations less than $0.5 \mathrm{~g} / 100 \mathrm{~g}$ fatty acids are grouped as 'minor', unless their concentrations were significantly different between the three groups. 
of circulating leptin and adiponectin by 87 and $85 \%$ respectively. Concomitant supplementation of FSO and CLA decreased the concentration of fasting plasma glucose by $20 \%(P \leq 0.05)$ when compared with that found in the CLA group. FSO supplementation along with CLA decreased the elevated circulating insulin, HOMA1-IR and HOMA1 for $\beta$ cell function to levels found in the control group (Table 4). However, it had no effect on the circulating concentrations of leptin and adiponectin. Neither of the fatty acid treatments altered the circulating concentrations of the inflammatory cytokines TNF $\alpha$ and IL-6.

\section{Discussion}

We tested the hypothesis of whether CLA-induced fatty liver and IR are aggravated by an inadequate intake of $n-3$ PUFA. The present results demonstrate that the small amount of ALA $(0.3 \mathrm{~g} / 100 \mathrm{~g}$ diet $)$ from FSO completely prevented the CLAinduced IR and significantly decreased the fasting plasma glucose concentration (Table 4). It also significantly reduced the development of fatty liver; however, it was not a complete prevention. The disparity of the effects of ALA on fatty liver and IR may suggest the involvement of different mechanism(s) or that a higher concentration of ALA may be needed to completely prevent the CLA-induced fatty liver than that required to prevent IR. Prevention of CLA-induced IR by ALA was associated with reversal of the changes in liver fatty acid composition induced by CLA. Dietary FSO increased the hepatic concentration of $n-6$ PUFA (linoleic acid, arachidonic acid and docosapentaenoic acid) and $n-3$ PUFA (ALA, EPA and DHA) and it decreased the $n-6: n-3$ PUFA ratio by $71 \%$. The most dramatic increases were in the concentrations of ALA and DHA, which most probably was the basis for improved insulin sensitivity. Therefore, we believe that the prevention of IR and NAFLD in the present study resulted from the increase in liver concentration of $n-3$ and not $n-6$ PUFA. Whether it was a direct effect of ALA or its elongation product (DHA) cannot be determined from the present results. Although addition of FSO to the diet created minor changes in other dietary fatty acids, the major change was an increase in the intake of ALA with a concomitant decrease in the $n-6: n-3$ ratio; hence we attribute the prevention of IR and fatty liver by FSO to the increase in the intake of ALA.

The present results showing the development of IR and fatty liver by CLA are consistent with those of previous animal studies $^{(20,21,24,26,27,29)}$. Effects of ALA on the CLA-induced fatty liver and IR in the present study are consistent with results from studies with fish oils and purified $\mathrm{DHA}^{(7,35,36)}$ and with those of ALA on the fatty liver induced by highfat or high-sucrose diets ${ }^{(37-39)}$.

A review of the published studies in which trans-10, cis-12CLA was used to induce IR and NAFLD in normal mice shows that many of these diets contained high concentrations of linoleic acid and were inadequate in ALA. Fat sources used in these studies included maize, sunflower-seed, safflowerseed and palm oils, which have insignificant amounts of $\operatorname{ALA}^{(20,26,30,36,46-50)}$. Other studies supplemented sunflowerseed oil with $0.1 \%$ linseed oil ${ }^{(51,52)}$, which failed to prevent the development of fatty liver. The concentration of linseed oil used in these studies may not be adequate, because it was only $20 \%$ of that used in our present study. Other investigators used soyabean oil $(6.5 \%)$, which has a linoleic acid: ALA ratio of $7: 1$, and still observed fatty liver and $\mathrm{IR}^{(29)}$; the development of IR and fatty liver in this study was most probably due to a relatively high concentration of CLA ( $1.5 \%$ as a mixture of isomers) compared with the low concentration of ALA. In general, the results of these studies support our hypothesis that fatty liver and IR induced by CLA may result from $n-3$ fatty acid deficiency.

The concentration of ALA $(0.3 \mathrm{~g} / 100 \mathrm{~g}$ diet $)$ used in the present study was smaller than the concentrations of DHA $(1.5 \mathrm{~g} / 100 \mathrm{~g}$ diet $)$ and fish oils $(6 \mathrm{~g} / 100 \mathrm{~g}$ diet $)$ previously reported to prevent CLA-induced fatty liver and $\operatorname{IR}^{(7,35)}$ A DHA concentration of $0.5 \mathrm{~g} / 100 \mathrm{~g}$ diet only partially prevented the increase in liver weight, and it failed to prevent IR

Table 4. Effect of experimental diets on plasma lipids, glucose, hormones and cytokines in mice (Mean values ( $n 10)$ with their standard errors for each variable measured)

\begin{tabular}{|c|c|c|c|c|c|c|}
\hline \multirow[b]{3}{*}{ Variable } & \multicolumn{6}{|c|}{ Dietary group } \\
\hline & \multicolumn{2}{|c|}{ Control } & \multicolumn{2}{|c|}{ CLA } & \multicolumn{2}{|c|}{$\mathrm{CLA}+\mathrm{FSO}$} \\
\hline & Mean & SEM & Mean & SEM & Mean & SEM \\
\hline Total cholesterol (mM) & $0.74^{a, b}$ & 0.06 & $0.91^{b}$ & 0.09 & $0.64^{a}$ & 0.04 \\
\hline HDL-cholesterol (mм) & $0.68^{a, b}$ & 0.07 & $0.82^{b}$ & 0.07 & $0.51^{a}$ & 0.08 \\
\hline LDL-cholesterol (mM) & $4 \cdot 2^{a, b}$ & 0.4 & $5 \cdot 2^{b}$ & 0.7 & $3 \cdot 4^{a}$ & 0.7 \\
\hline TAG (mM) & $9 \cdot 4^{\mathrm{c}}$ & 1.9 & $5 \cdot 8^{\mathrm{b}}$ & $2 \cdot 3$ & $2 \cdot 5^{a}$ & 0.7 \\
\hline NEFA (mM) & 0.47 & 0.05 & 0.37 & 0.03 & 0.32 & 0.03 \\
\hline Glucose (mм) & $11 \cdot 0^{\mathrm{b}}$ & 0.52 & $11 \cdot 4^{b}$ & 0.54 & $9 \cdot 10^{\mathrm{a}}$ & 0.47 \\
\hline Adiponectin $(\mu \mathrm{g} / \mathrm{ml})$ & $22 \cdot 3^{b}$ & 1.44 & $3 \cdot 4^{\mathrm{a}}$ & 0.30 & $3 \cdot 5^{\mathrm{a}}$ & 0.3 \\
\hline Leptin (ng/ml) & $3 \cdot 38^{\mathrm{b}}$ & 0.90 & $0.44^{\mathrm{a}}$ & 0.08 & $0.39^{a}$ & 0.09 \\
\hline Insulin (pg/ml) & $235^{a}$ & 120 & $1729^{b}$ & 829 & $239^{a}$ & 58 \\
\hline HOMA1-IR & $0.97^{a}$ & 0.40 & $10 \cdot 5^{b}$ & 4.98 & $1 \cdot 05^{a}$ & 0.30 \\
\hline HOMA1-\% B & $34 \cdot 11^{a}$ & $14 \cdot 01$ & $364 \cdot 3^{b}$ & $170 \cdot 5$ & $36 \cdot 87^{a}$ & $10 \cdot 43$ \\
\hline IL-6 (pg/ml) & $2 \cdot 06$ & 0.36 & $2 \cdot 10$ & 0.26 & $2 \cdot 80$ & 0.78 \\
\hline $\mathrm{TNF}_{\alpha}(\mathrm{pg} / \mathrm{ml})$ & $1 \cdot 81$ & 0.20 & 1.49 & 0.25 & 2.03 & 0.59 \\
\hline
\end{tabular}

CLA, trans-10, cis-12-conjugated linoleic acid; FSO, flaxseed oil; HOMA1-IR, homeostatic model assessment 1 for insulin resistance; HOMA1-\% $\mathrm{B}$, homeostatic model assessment 1 for $\beta$ cell function.

${ }^{a, b, c}$ Mean values within a row with unlike superscript letters were significantly different $(P \leq 0.05 ;$ ANOVA; $a<b<c)$. 
in an earlier study in mice where NAFLD and IR were induced by feeding a mixture of CLA isomers $(2 \mathrm{~g} / 100 \mathrm{~g} \text { diet })^{(50)}$. The results of the present and those of previously published studies ${ }^{(7,35,50)}$ suggest that ALA may have a direct effect and may be more effective than DHA or fish oils in preventing IR. It is also possible that the prevention of IR and NAFLD in the present study resulted from an increase in liver DHA, because the liver DHA concentration in the FSO group was comparable with DHA concentration in the livers from the control group (Table 3). Further studies with increasing concentrations of DHA and ALA are needed to determine the minimum dose of the $n-3$ PUFA needed to prevent the NAFLD and IR induced by a known concentration of trans-10, cis-12-CLA. Body weights in both the CLA and CLA + FSO groups were significantly lower than that in the control group, and it did not differ between the CLA and CLA + FSO groups (Fig. 1). Further studies are also needed to determine the specific ratios between dietary CLA and ALA that may reduce body and adipose tissue weights without causing IR, NAFLD, or other adverse effects of CLA.

Studies in mice have reported that the hyperinsulinaemia seen after CLA supplementation was preceded by decreases in plasma leptin and adiponectin ${ }^{(7,24,27,35)}$. It has also been reported that maintaining leptin or adiponectin in the CLAfed mice attenuated CLA-induced $\mathrm{IR}^{(29,53)}$. In the present study, concentrations of both circulating leptin and adiponectin were reduced by 85 and $87 \%$ by CLA supplementation (Table 4); concomitant supplementation of CLA and FSO failed to prevent the CLA-induced decline in circulating concentrations of both leptin and adiponectin, yet it maintained the circulating insulin concentrations to levels found in the control group. These findings suggest that the effects of ALA on the prevention of fatty liver and IR may be independent of both leptin and adiponectin. These effects of ALA on circulating concentrations of leptin and adiponectin differ from those of DHA which partially restored the concentrations of both leptin and adiponectin in mice fed CLA-containing diets $^{(7)}$. The present results that showed no change in the concentrations of circulating TNF $\alpha$ and IL- 6 by the feeding of trans-10, cis-12-CLA are at variance with those of others who reported increased expression of these cytokines in liver and adipose tissue ${ }^{(54,55)}$. This discrepancy may be due to site-specific effects of CLA.

We are not sure about the underlying mechanism(s) by which CLA increased and ALA reduced the plasma insulin concentrations. CLA feeding in mice has been reported to cause pancreatic $\beta$ cell hyperplasia with a concomitant increase in insulin secretion in vivo ${ }^{(28)}$. $\beta$ Cells isolated from mice fed CLA-containing diets and then cultured ex vivo demonstrated an increased secretion of insulin as compared with that observed in cells isolated from animals fed a diet without CLA $^{(36)}$. Hence, changes in concentrations of circulating insulin caused by CLA and ALA in the present study may reflect the changes in insulin secretion. The reduction in fasting glucose caused by ALA may be due to increased insulin sensitivity and/or decreased glucose output by the liver. In rats fed fish oil-containing diets, DHA was the major $n-3$ PUFA that accumulated in liver and it suppressed hepatocyte levels of sterol regulatory element binding protein-1 (SREBP-1) nuclear abundance, SREBP-1c mRNA and Insig- 2 mRNA $^{(56)}$. Thus, the reduction in liver fat caused by DHA formed from ALA in the present study may be due to a decreased expression of SREBP-1, which controls hepatic lipogenesis.

In summary, the results of the present study show that a relatively small amount of ALA $(0.3 \mathrm{~g} / 100 \mathrm{~g}$ diet $v$. CLA at $0.5 \mathrm{~g} / 100 \mathrm{~g}$ diet) completely prevented the CLA-induced IR and partially prevented the CLA-induced fatty liver. ALA increased the $n-3$ and $n-6$ PUFA and markedly reduced the $n-6: n-3$ PUFA ratio in liver lipids. These effects of ALA were independent of the changes in the concentrations of circulating leptin and adiponectin. Future studies are needed to determine the response of fatty liver and IR to increasing concentrations of ALA and DHA to distinguish between the direct effects of ALA and its elongation products (EPA and DHA), to determine the clinical relevance of ALA in the management of IR and fatty liver and to understand the mechanisms involved.

\section{Acknowledgements}

The funds for the present study were provided by the US Department of Agriculture. The authors have no conflicts of interest to disclose. D. S. K., M. V. and B. E. M. designed and planned the study; M. V., Y. A., S. S. G. and D. F. conducted the study and performed the sample analysis; D. S. K., M. V., Y. A., B. E. M. and D. F. analysed the data and prepared the manuscript.

References to a company or product name do not imply approval or recommendation of the product by the US Department of Agriculture to the exclusion of others that may be suitable.

\section{References}

1. Moller DE \& Flier JS (1991) Insulin resistance - mechanisms, syndromes, and implications. N Engl J Med 325, 938-948.

2. Marchesini G, Brizi M, Morselli-Labate AM, Bianchi G, Bugianesi E, McCullough AJ, Forlani G \& Melchionda N (1999) Association of nonalcoholic fatty liver disease with insulin resistance. Am J Med 107, 450-455.

3. Smith SC Jr (2007) Multiple risk factors for cardiovascular disease and diabetes mellitus. Am J Med 120, Suppl. 1, S3-S11.

4. Li C, Ford ES, McGuire LC, Mokdad AH, Little RR \& Reaven GM (2006) Trends in hyperinsulinemia among nondiabetic adults in the U.S. Diabetes Care 29, 2396-2402.

5. Adams LA \& Lindor KD (2007) Nonalcoholic fatty liver disease. Ann Epidemiol 17, 863-869.

6. Zivkovic AM, German JB \& Sanyal AJ (2007) Comparative review of diets for the metabolic syndrome: implications for nonalcoholic fatty liver disease. Am J Clin Nutr 86, 285-300.

7. Vemuri M, Kelley DS, Mackey BE, Rasooly R \& Bartolini G (2007) Docosahexaenoic acid (DHA) but not eicosapentaenoic acid (EPA) prevents trans-10, cis-12 conjugated linoleic acid (CLA)-induced insulin resistance in mice. Metab Syndr Relat Dis 5, 315-322.

8. Bloomgarden ZT (2005) Insulin resistance: causes and consequences. Int Rev Neurobiol 65, 1-24.

9. Angulo P (2002) Nonalcoholic fatty liver disease. N Engl J Med 346, $1221-1231$.

10. Bloomgarden ZT (2005) Concepts of insulin resistance. Metab Syndr Relat Dis 3, 284-293.

11. Lee JS, Pinnamaneni SK, Eo SJ, Cho IH, Pyo JH, Kim CK, Sinclair AJ, Febbraio MA \& Watt MJ (2006) Saturated, but not $n-6$ polyunsaturated, fatty acids induce insulin resistance: 
role of intramuscular accumulation of lipid metabolites. J Appl Physiol 100, 1467-1474.

12. Lovejoy JC (2002) The influence of dietary fat on insulin resistance. Curr Diab Rep 2, 435-440.

13. Petersen KF \& Shulman GI (2006) Etiology of insulin resistance. Am J Med 119, S10-S16.

14. Kris-Etherton PM, Innis S \& American Dietetic Association \& Dietitians of Canada (2007) Position of the American Dietetic Association and Dietitians of Canada: dietary fatty acids. $J \mathrm{Am}$ Diet Assoc 107, 1599-1611.

15. Parodi PW (2003) Conjugated linoleic acid in food. In Advances in Conjugated Linoleic Acid Research, vol. 2, pp. 101-122 [JL Sebedio, WW Christie and R Adlof, editors]. Champaign, IL: AOCS Press.

16. Jung MY \& Ha YL (1999) Conjugated linoleic acid isomers in partially hydrogenated soybean oil obtained during nonselective and selective hydrogenation processes. J Agric Food Chem 47, 704-708.

17. Kelley DS \& Erickson KL (2003) Modulation of body composition and immune cell functions by conjugated linoleic acid in humans and animal models: benefits vs. risks. Lipids 38, 377-386.

18. Tricon S, Burdge GC, Williams CM, Calder PC \& Yaqoob P (2005) The effects of conjugated linoleic acid on human health-related outcomes. Proc Nutr Soc 64, 171-182.

19. Wahle KW, Heys SD \& Rotondo D (2004) Conjugated linoleic acids: are they beneficial or detrimental to health? Prog Lipid Res 43, 553-587.

20. Clement L, Poirier H, Niot I, Bocher V, Guerre-Millo M, Krief S, Staels B \& Besnard P (2002) Dietary trans-10, cis-12 conjugated linoleic acid induces hyperinsulinemia and fatty liver in the mouse. J Lipid Res 43, 1400-1409.

21. Hargrave KM, Azain MJ, Kachman SD \& Miner JL (2003) Conjugated linoleic acid does not improve insulin tolerance in mice. Obes Res 11, 1104-1115.

22. Medina EA, Horn WF, Keim NL, Havel PJ, Benito P, Kelley DS, Nelson GJ \& Erickson KL (2000) Conjugated linoleic acid supplementation in humans: effects on circulating leptin concentrations and appetite. Lipids 35, 783-788.

23. Moloney F, Yeow TP, Mullen A, Nolan JJ \& Roche HM (2004) Conjugated linoleic acid supplementation, insulin sensitivity, and lipoprotein metabolism in patients with type 2 diabetes mellitus. Am J Clin Nutr 80, 887-895.

24. Poirier H, Rouault C, Clement L, Niot I, Monnot MC, Guerre-Millo M \& Besnard P (2005) Hyperinsulinaemia triggered by dietary conjugated linoleic acid is associated with a decrease in leptin and adiponectin plasma levels and pancreatic $\beta$ cell hyperplasia in the mouse. Diabetologia 48, 1059-1065.

25. Riserus U, Vessby B, Arner P \& Zethelius B (2004) Supplementation with trans 10 cis12-conjugated linoleic acid induces hyperproinsulinaemia in obese men: close association with impaired insulin sensitivity. Diabetologia 47, 1016-1019.

26. Kelley DS, Bartolini GL, Warren JM, Simon VA, Mackey BE \& Erickson KL (2004) Contrasting effects of t10,c12- and c9,t11conjugated linoleic acid isomers on the fatty acid profiles of mouse liver lipids. Lipids 39, 135-141.

27. Ohashi A, Matsushita Y, Kimura K, Miyashita K \& Saito M (2004) Conjugated linoleic acid deteriorates insulin resistance in obese/diabetic mice in association with decreased production of adiponectin and leptin. J Nutr Sci Vitaminol (Tokyo) 50, 416-421.

28. Poirier H, Niot I, Clement L, Guerre-Millo M \& Besnard P (2005) Development of conjugated linoleic acid (CLA)-mediated lipoatrophic syndrome in the mouse. Biochimie 87, 73-79.

29. Purushotham A, Wendel AA, Liu LF \& Belury MA (2007) Maintenance of adiponectin attenuates insulin resistance induced by dietary conjugated linoleic acid in mice. $J$ Lipid Res 48, 444-452.
30. Kelley DS, Bartolini GL, Newman JW, Vemuri M \& Mackey BE (2006) Fatty acid composition of liver, adipose tissue, spleen, and heart of mice fed diets containing t10, c12-, and c9, t11-conjugated linoleic acid. Prostaglandins Leukot Essent Fatty Acids 74, 331-338.

31. El-Badry AM, Graf R \& Clavien PA (2007) Omega 3 - omega 6: what is right for the liver? $J$ Hepatol 47, 718-725.

32. Delarue J, LeFoll C, Corporeau C \& Lucas D (2004) n-3 Long chain polyunsaturated fatty acids: a nutritional tool to prevent insulin resistance associated to type 2 diabetes and obesity? Reprod Nutr Dev 44, 289-299.

33. Flachs P, Mohamed-Ali V, Horakova O, Rossmeisl M, Hosseinzadeh-Attar MJ, Hensler M, Ruzickova J \& Kopecky J (2006) Polyunsaturated fatty acids of marine origin induce adiponectin in mice fed a high-fat diet. Diabetologia 49, 394-397.

34. Rossi AS, Lombardo YB, Lacorte JM, Chicco AG, Rouault C, Slama G \& Rizkalla SW (2005) Dietary fish oil positively regulates plasma leptin and adiponectin levels in sucrose-fed, insulin-resistant rats. Am J Physiol Regul Integr Comp Physiol 289, R486-R494.

35. Ide $\mathrm{T}$ (2005) Interaction of fish oil and conjugated linoleic acid in affecting hepatic activity of lipogenic enzymes and gene expression in liver and adipose tissue. Diabetes 54, 412-423.

36. Winzell MS, Pacini G \& Ahren B (2006) Insulin secretion after dietary supplementation with conjugated linoleic acids and $n-3$ polyunsaturated fatty acids in normal and insulin-resistant mice. Am J Physiol Endocrinol Metab 290, E347-E354.

37. Murase T, Aoki M \& Tokimitsu I (2005) Supplementation with $\alpha$-linolenic acid-rich diacylglycerol suppresses fatty liver formation accompanied by an up-regulation of $\beta$-oxidation in Zucker fatty rats. Biochim Biophys Acta 1733, 224-231.

38. Mustad VA, Demichele S, Huang YS, Mika A, Lubbers N, Berthiaume N, Polakowski J \& Zinker B (2006) Differential effects of $n-3$ polyunsaturated fatty acids on metabolic control and vascular reactivity in the type 2 diabetic ob/ob mouse. Metabolism 55, 1365-1374.

39. Ghafoorunissa, Ibrahim A, Rajkumar L \& Acharya V (2005) Dietary (n-3) long chain polyunsaturated fatty acids prevent sucrose-induced insulin resistance in rats. $J$ Nutr $\mathbf{1 3 5}$, 2634-2638.

40. Reeves PG, Nielsen FH \& Fahey GC Jr (1993) AIN-93 purified diets for laboratory rodents: final report of the American Institute of Nutrition ad hoc writing committee on the reformulation of the AIN-76A rodent diet. J Nutr 123, 1939-1951.

41. Kelley DS, Warren JM, Simon VA, Bartolini G, Mackey BE \& Erickson KL (2002) Similar effects of c9,t11-CLA and t10,c12-CLA on immune cell functions in mice. Lipids 37, $725-728$.

42. Wallace TM, Levy JC \& Matthews DR (2004) Use and abuse of HOMA modeling. Diabetes Care 27, 1487-1495.

43. Box GEP, Hunger WG \& Hunter JS (1978) Statistics for Experimenters: An Introduction to Design, Data Analysis, and Model Building. New York: Wiley.

44. SAS Institute, Inc. (2004) SAS Online Doc 9.1.3 ed. Cary, NC: SAS Institute, Inc.

45. Littell RC, Milliken GA, Stroup WW, Wolfinger RD \& Schabenberger O (editors) (2006) SAS System for Mixed Models, 2nd ed. Cary, NC: SAS Institute, Inc.

46. Javadi M, Beynen AC, Hovenier R, Lankhorst A, Lemmens AG, Terpstra AH \& Geelen MJ (2004) Prolonged feeding of mice with conjugated linoleic acid increases hepatic fatty acid synthesis relative to oxidation. $J$ Nutr Biochem 15, 680-687.

47. Roche HM, Noone E, Sewter C, McBennett S, Savage D, Gibney MJ, O'Rahilly S \& Vidal-Puig AJ (2002) Isomerdependent metabolic effects of conjugated linoleic acid: insights from molecular markers sterol regulatory element-binding protein-1c and LXR $\alpha$. Diabetes 51, 2037-2044. 
48. Takahashi Y, Kushiro M, Shinohara K \& Ide T (2003) Activity and mRNA levels of enzymes involved in hepatic fatty acid synthesis and oxidation in mice fed conjugated linoleic acid. Biochim Biophys Acta 1631, 265-273.

49. Tsuboyama-Kasaoka N, Takahashi M, Tanemura K, Kim HJ, Tange T, Okuyama H, Kasai M, Ikemoto S \& Ezaki O (2000) Conjugated linoleic acid supplementation reduces adipose tissue by apoptosis and develops lipodystrophy in mice. Diabetes 49, 1534-1542.

50. Yanagita T, Wang YM, Nagao K, Ujino Y \& Inoue N (2005) Conjugated linoleic acid-induced fatty liver can be attenuated by combination with docosahexaenoic acid in C57BL/6N mice. J Agric Food Chem 53, 9629-9633.

51. Degrace P, Demizieux L, Gresti J, Chardigny JM, Sebedio JL \& Clouet P (2003) Association of liver steatosis with lipid oversecretion and hypotriglyceridaemia in C57BL/6J mice fed trans10,cis-12-linoleic acid. FEBS Lett 546, 335-339.

52. Degrace P, Demizieux L, Gresti J, Chardigny JM, Sebedio JL \& Clouet P (2004) Hepatic steatosis is not due to impaired fatty acid oxidation capacities in C57BL/6J mice fed the conjugated trans-10,cis-12-isomer of linoleic acid. $J$ Nutr 134, 861-867.

53. Toyoshima Y, Gavrilova O, Yakar S, Jou W, Pack S, Asghar Z, Wheeler MB \& LeRoith D (2005) Leptin improves insulin resistance and hyperglycemia in a mouse model of type 2 diabetes. Endocrinology 146, 4024-4035.

54. Poirier H, Shapiro JS, Kim RJ \& Lazar MA (2006) Nutritional supplementation with trans-10, cis-12-conjugated linoleic acid induces inflammation of white adipose tissue. Diabetes 55, $1634-1641$.

55. Cai D, Yuan M, Frantz DF, Melendez PA, Hansen L, Lee J \& Shoelson SE (2005) Local and systemic insulin resistance resulting from hepatic activation of IKK- $\beta$ and NF-кB. Nat Med 11, 183-190.

56. Botolin D, Wang Y, Christian B \& Jump DB (2006) Docosahexaneoic acid $(22: 6, n-3)$ regulates rat hepatocyte SREBP-1 nuclear abundance by Erk- and $26 \mathrm{~S}$ proteasome-dependent pathways. J Lipid Res 47, 181-192. 